\title{
Da Legitimidade do Ministério Público para propor Ação Civil Pública relativa à Contribuição para o Custeio de Iluminação Pública
}

\author{
The Legitimacy of the Public Ministry to propose Public Civil Action related to the \\ Contribution for the Cost of Public Lighting
}

\author{
Karina Mayumi Oquendo ${ }^{1}$ \\ Luciane Pereira de Oliveira²
}

\section{Resumo}

\begin{abstract}
O presente artigo tem como tema a legitimidade do Ministério Público para propor Ação Civil Pública na defesa dos interesses transindividuais de ordem tributária, especificamente em relação à Contribuição para o Custeio de lluminação Pública. As questões controvertidas sobre a COSIP, tributo previsto no art. 149-A da Constituição Federal, fundamentam a sequente asserção de sua inconstitucionalidade, por ofensa às cláusulas pétreas, bem como, aos direitos e garantias individuais do contribuinte e aos princípios constitucionais tributários. Após a explanação sobre o tributo, o estudo prossegue com o auxílio da doutrina e da legislação, na conceituação da Ação Civil Pública e do Ministério Público, como também, disserta sobre a matéria dos interesses difusos, coletivos e do interesse individual homogêneo. Em conclusão, explicita que a finalidade pretendida pelo Ministério Público na defesa dos interesses transindividuais aperfeiçoar-se-á com o reconhecimento de sua legitimidade nas questões tributárias, em destaque, no debate em relação à COSIP, por meio da Ação Civil Pública.
\end{abstract}

Palavras Chave: COSIP. Ação Civil Pública. Legitimidade. Ministério Público.

\begin{abstract}
The present article has as its theme the legitimacy of Public Ministry to propose Public Civil Action to defend the collective interests in tributary order, specifically in relation to the Contribution for the Cost of Public Lighting. The controversial issues about the CCPL, tribute provided in the Article 149-A of the Federal Constitution, support the sequent assertion of its unconstitutionality, by the offense of the immutable clauses, as well as, the individual rights and guarantees of the taxpayer and the tributary constitutional principles. After the tribute explanation, the study continues with the aid of the doctrine and the legislation, in conceptualizing the Public Civil Action and the Public Ministry, and also, disserted the matter of the diffuse, collective and individual homogeneous interests. In conclusion, it states that the purpose intended by the Public Ministry to defend the collective interests will improve with the recognition of its legitimacy on tributary matter, in focus, on the debate related to CCPL through the Public Civil Action.
\end{abstract}

Pós-graduanda em Direito Civil e Processo Civil pela Universidade Estadual de Londrina; graduada em Direito pela Universidade Estadual de Londrina.

2 Pós-graduanda em Direito Civil e Processo Civil pela Universidade Estadual de Londrina; graduada em Direito pela Universidade Estadual de Londrina. 
Key words: CCPL. Public Civil Action. Legitimacy. Public Ministry.

\section{Introdução}

A Contribuição para o Custeio de Iluminação Pública - COSIP - é um tributo previsto no art. 149-A da Constituição Federal, dispositivo incluído pela Emenda Constitucional no 39/2002, estabelecida para o custeio do serviço de iluminação pública que pode ser instituída pelos Municípios e Distrito Federal.

A COSIP possui características de outras espécies tributárias, pois tem semelhanças com a taxa e com o imposto, sendo a divergência doutrinária sobre sua natureza abordada no presente trabalho.

Outro ponto do estudo é a não observância pelo legislador da EC no 39/2002 dos ditames expressos pelo Poder Constituinte Originário ao modificar a competência de instituir tributos, pois trata-se de cláusula pétrea, cuja alteração está vedada no art. 60, §4으 da Carta Magna.

Também, os direitos e garantias individuais do contribuinte relacionados aos princípios constitucionais tributários devem ser resguardados pela Constituição Federal, do contrário nota-se flagrante caso de inconstitucionalidade, como será demonstrado em relação à COSIP.

Para o questionamento das matérias polêmicas em relação à COSIP, será legítimo o Ministério Público, agindo na defesa de interesses transindividuais mediante proposição da Ação Civil Pública.

A Ação Civil Pública é instrumento da cidadania, uma vez que tutela os interesses coletivos, difusos e individuais homogêneos, os quais são, doutrinariamente, denominados de interesses transindividuais, sendo o Ministério Público encarregado de proteger os direitos fundamentais do Estado Democrático de Direito e, juntamente com outros colegitimados, possui a titularidade para propor a Ação Civil Pública.

Todavia, a Medida Provisória no 2.180-35/ 2001, vedou a propositura da Ação Civil Pública em matéria tributária, o que impossibilitou a discussão de assuntos de suma relevância para os contribuintes, bem como, o oferecimento desta ação pelo Ministério Público. 
O presente estudo visa demonstrar a legitimidade do Ministério Público para propor a Ação Civil Pública sempre que houver lesão ou ameaça de lesão a interesses transindividuais, como no caso a ser explanado da COSIP.

\section{Da Contribuição para o Custeio de Iluminação Pública - COSIP}

As contribuições previstas no art. 149 da Constituição Federal têm natureza tributária, pois estão entre as demais espécies tributárias dispostas no Título VI - Da Tributação e do Orçamento, no Capítulo I - Do Sistema Tributário Nacional, na Seção I - Dos Princípios Gerais.

A localização na Constituição Federal demonstra a contribuição como um tributo, como também, através da exposição dos princípios gerais do sistema, que são: o princípio das espécies tributárias (arts. 145, 148 e 149 da CF); o princípio da capacidade contributiva (art. 145, § 10 da CF) e o princípio da lei complementar (art. 148 da CF). (MARTINS, 2003, p. 340).

Desta forma, sendo competência da União instituir contribuições sociais, de intervenção no domínio econômico e de interesse das categorias profissionais ou econômicas, e por constituírem uma das espécies tributárias, conclui-se pela classificação quinquipartida dos tributos: impostos, taxas, contribuição de melhoria, empréstimos compulsórios e contribuições.

A importância dessa classificação está na intenção do legislador constituinte de prescrever manifestamente que as contribuições são entidades tributárias, subordinando-se em tudo e por tudo às linhas definitórias do regime constitucional peculiar aos tributos. (CARVALHO, 2011, p. 75).

As contribuições previstas no art. 149 da Constituição Federal são de competência da União, porém o art. 149-A estabelece uma espécie de tributo que pode ser instituído pelos Municípios e Distrito Federal:

Art. 149-A Os Municípios e o Distrito Federal poderão instituir contribuição, na forma das respectivas leis, para o custeio do serviço de iluminação pública, observado o disposto no art. 150, I e III. (Incluído pela Emenda Constitucional no 39, de 2002).

Parágrafo único. É facultada a cobrança da contribuição a que se refere o caput, na fatura de consumo de energia elétrica. (Incluído pela Emenda Constitucional no 39, de 2002) (BRASIL, 2010b). 
O dispositivo foi incluído pela Emenda Constitucional no 39, promulgada pelo Congresso Nacional em 19 de dezembro de 2002, estabelecendo a Contribuição para o Custeio de lluminação Pública - COSIP.

Primeiramente, importante ressaltar que referida contribuição tem natureza jurídico-tributária, pois tipifica uma obrigação compulsória de dar moeda, não constitui sanção por ato ilícito, é estabelecida por lei e exigida nos seus termos, sendo um tributo toda prestação pecuniária compulsória, em moeda ou cujo valor nela se possa exprimir, que não constitua sanção de ato ilícito, instituída em lei e cobrada mediante atividade administrativa plenamente vinculada, nos moldes do art. 3 o do Código Tributário Nacional. (BRASIL, 2010a).

A COSIP, apesar de estar disposta no art. 149-A da Constituição Federal, não constitui uma espécie de contribuição prevista no caput do artigo em questão, pois além de ser de competência dos Municípios e do Distrito Federal, visa custear o serviço de iluminação pública local, e não intervir no domínio econômico, atender a interesses de categorias profissionais ou econômicas ou custear a Seguridade Social, finalidades essas das contribuições (CARRAZZA, 2010, p. 661-662).

Nos dizeres de Ives Gandra da Silva Martins (apud BARRETO, 2009, p. 516), a COSIP, por não expressar quem será o contribuinte, qual o tipo de iluminação pública, em que espaço poderá ser utilizado, e se, no caso de a energia ser fornecida pelo Estado, caberá aos Municípios o poder de cobrar o tributo, além de inúmeros outros aspectos não estarem conformados pelo texto maior, faz com que a doutrina a classifique como outra espécie de tributo.

Assim, tem-se que a mera denominação de "contribuição" não espelha as reais características do tributo. A contribuição se assemelha a uma taxa, com nuances de imposto, afirma Aires F. Barreto (2009, p. 517) ao seguir a posição de Ives Gandra da Silva Martins que demonstra a insuficiência das semelhanças com uma "taxa", pois a contribuição do art. 149A da CF: “[...] é pura, e simplesmente, tributo destinado a cobrir prestação de serviço, nem se furtando, o desajeitado constituinte, a reconhecer que sua cobrança 'é para o custeio do serviço de iluminação pública'."

Além de se enquadrar em uma contraprestação a um serviço público, caracterizando uma 'taxa', o legislador só estabeleceu a 'forma' de cobrança, mas não da 
conformação do tributo, ao prever a cobrança da contribuição na fatura de consumo de energia elétrica (BARRETO, 2009, p. 517).

O art. 149-A da Constituição Federal não indicou a materialidade, mas apenas o objetivo a ser alcançado pela contribuição: o custeio do serviço de iluminação pública, ou seja, iluminação das ruas, praças, avenidas, parques e demais bens de uso comum (CARRAZA, 2010, p. 661).

Porém, é possível notar que a COSIP não reveste a natureza jurídica da taxa de serviço, pois segundo o doutrinador Roque Antonio Carrazza (2010, p. 661): "[...] não deflui da prestação de qualquer serviço público específico e divisível, prestado ao contribuinte ou posto à sua disposição. Inexistem, em suma, quaisquer divisibilidade e especificidade no serviço de iluminação pública."

Também já decidiu o Supremo Tribunal Federal pela inconstitucionalidade da Taxa de Iluminação Pública, expressa na Súmula no 670: "O serviço de iluminação pública não pode ser remunerado mediante taxa" (BRASIL, 2003).

Por se revestir do nome "contribuição", caracteriza-se a espécie tributária como “imposto", porém um imposto com destinação específica, conforme adverte José Eduardo Soares de Melo (2006, p. 113) que a contribuição não atende aos pressupostos para a sua previsão normativa "[...] uma vez que não direciona a um grupo determinado de pessoas (ao contrário, atende a um número infinito de pessoas), não causa benefício especial ao contribuinte (mas a coletividade), e nem se vincula a uma determinada entidade."

Corrobora com esse entendimento, ao afirmar que a contribuição do art. 149-A da Constituição Federal é um imposto, Roque Antonio Carrazza (2010, p. 662): “[...] já que tem por materialidade o fato de uma pessoa, física ou jurídica, estar fixada no local (Município ou Distrito Federal) onde é prestado o serviço de iluminação pública. Trata-se, pois, de um tributo não vinculado a uma atuação estatal."

Importante ressaltar que mesmo com a insuficiência de elementos para a aplicação da contribuição do art. 149-A, é possível determinar o critério material - a propriedade, a posse, o domínio útil ou o direito de superfície de imóvel situado na zona urbana ou rural do Município ou Distrito Federal; o critério espacial - serviço de iluminação pública prestado no território da pessoa política onde se encontra de algum modo ligado o contribuinte; sujeito passivo - pessoa que reside, está domiciliada, mantém imóvel ou desenvolve atividades 
profissionais no local onde é prestado o serviço de iluminação pública; critério quantitativo deverá ser variável, conforme o imóvel ocupado pelo contribuinte seja residencial, comercial, industrial, rural, determinando assim a alíquota e a base de cálculo, que é um valor que deve seguir critérios ditados pela razoabilidade e a capacidade econômica do contribuinte (CARRAZZA, 2010, p. 662-663).

Logo, a Contribuição para o Custeio de Iluminação Pública estabelecida no art. 149A da Constituição Federal, apesar de ser denominada 'contribuição' não possui caráter jurídico dessa espécie de tributo, sendo assemelhada ao imposto em diversos elementos.

\section{Princípios Constitucionais}

O art. 149-A da Constituição Federal prevê que a Contribuição para o Custeio de Iluminação Pública deve observar o disposto no art. 150, I e III da Constituição, ou seja, os princípios da legalidade, da irretroatividade e da anterioridade.

O princípio da isonomia previsto no art. 150, II da Constituição não consta como um dos princípios a serem observados pela COSIP, porém como um tributo, a contribuição deve respeitar todos os princípios constitucionais tributários, dentre eles o da capacidade contributiva disposta no art. 145, §1ㅇ da Constituição.

Antes de discorrer sobre tais princípios, importante mencionar que os princípios decorrem da Constituição, que em resumo "[...] fixa as diretrizes, implícitas e explícitas, a serem observadas por todos (membros dos Poderes Executivo, Legislativo e Judiciário etc.), sob pena de se tornarem sem efeito os atos praticados" (CARRAZZA, 2010, p. 35-36).

Assim, os princípios têm a função de adequar a interpretação das normas para que sua finalidade seja atingida, visando colaborar para efetividade das mesmas, ressaltando que os princípios jurídicos atuam em conjunto, não isoladamente.

Aires F. Barreto (2009, p. 19) constata que a consequência é de que as regras têm sua "[...] interpretação e eficácia condicionadas pelos princípios, que se harmonizam em função da hierarquia entre eles estabelecida, de modo a assegurar plena coerência interna ao sistema, como engrenagens plenamente ajustadas umas às outras."

Por conseguinte, a contribuição prevista no art. 149-A da CF não deve se sujeitar somente aos princípios previstos art. 150, I e III da CF, mas sim, aos princípios constitucionais 
tributários, especificamente ao princípio da isonomia e ao princípio da capacidade contributiva.

O princípio da isonomia previsto no art. 150, II da CF tem relação com o princípio republicano, o qual exige que os contribuintes recebam tratamento isonômico, demonstrando que para a efetividade da Constituição os princípios devem se relacionar.

A forma de governo da República faz validar um princípio constitucional para todo o ordenamento jurídico, pois leciona Geraldo Ataliba (apud ARAUJO, 2008, p. 102): “A simples menção ao termo república já evoca um universo de conceitos intimamente relacionados entre si, sugerindo a noção do princípio jurídico que a expressão quer designar."

Assim, também ensina Roque Antonio Carrazza (2010, p. 86-87):

\begin{abstract}
A lei tributária deve ser igual para todos e a todos deve ser aplicada com igualdade. Melhor expondo, quem está na mesma situação jurídica deve receber o mesmo tratamento tributário. Será inconstitucional - por burlar ao princípio republicano e ao da isonomia - a lei tributária que selecione pessoas, para submetê-las a regras peculiares, que não alcançam outras, ocupantes de idênticas posições jurídicas.
\end{abstract}

Já o princípio da capacidade contributiva, previsto no art. $145, \S 1$ 으 da CF, para Paulo de Barros Carvalho (2011, p. 215) consiste em estabelecer "[...] o padrão de referência básico para aferir-se o impacto da carga tributária e o critério comum dos juízos de valor sobre o cabimento e a proporção do expediente impositivo."

Logo, há a necessidade de demonstrar fatos que identifiquem o patrimônio, os rendimentos e as atividades econômicas do contribuinte, para a distribuição da carga tributária de modo uniforme e com satisfatória atinência ao princípio da igualdade (CARVALHO, 2011, p. 215).

Os princípios constitucionais tributários integram o rol das cláusulas pétreas, aqueles entendidos como verdadeiras exteriorizações de direitos e garantias individuais dos contribuintes constitucionalmente positivados (BONFIM, 2004).

Alexandre de Morais (apud BONFIM, 2004) define os direitos individuais como sendo: "[...] disposições meramente declaratórias, que são as que exprimem existência legal aos direitos reconhecidos, e as garantias, como as disposições assecuratórias, que são as que, em defesa dos direitos, limitam o poder".

Importante observar a definição das cláusulas pétreas, sendo "[...] postulados e princípios constitucionais que por representarem as vigas-mestras da estrutura federativa e 
republicana e a espinha dorsal da segurança jurídica dos cidadãos, remanescem inalteráveis" (SAHID apud BARRETO, 2009, p. 509).

Desta forma, os princípios constitucionais tributários são considerados cláusulas pétreas não só porque são princípios constitucionais, "[...] mas também e principalmente porque agregam, incorporam, direitos ao patrimônio jurídico dos contribuintes, servindo, em sua totalidade, como verdadeiras garantias dos cidadãos em face do Poder do Estado" (BONFIM, 2004).

Referidas garantias estão presentes na Constituição Federal, que veda a proposta de Emenda à Constituição tendente a abolir tais direitos e garantias individuais, conforme previsão em seu art. 60, §4으, IV.

Pertinente mencionar que a Constituição Federal de 1988 "é rígida, só admitindo a sua modificação através de processo e solenidades especiais para introdução de emenda constitucional, alteração essa defesa relativamente às cláusulas pétreas dispostas pelo Texto Supremo, em seu art. 60" (BARRETO, 2009, p. 509).

Além disso, estão presentes na Constituição exigências para sua alteração pelo chamado Poder Constituinte Derivado, que apresenta características de limitação - limites a sua alteração, criando determinadas áreas imutáveis, que são as cláusulas pétreas do art. 60, $\S 4$ 으 e a condicionalidade - a modificação da Constituição deve obedecer ao processo determinado para sua alteração, que é o processo de emenda (ARAÚJO, 2008, p. 10).

Portanto, as espécies de tributos devem seguir não só os princípios constitucionais, mas também e principalmente os princípios constitucionais tributários, resguardando os direitos e garantias individuais como cláusulas pétreas, impossibilitando assim qualquer tipo de mudança no que foi previsto pelo Poder Constituinte Originário.

Destarte, a Contribuição para o Custeio de Iluminação Pública prevista no art. 149-A da CF, dispositivo incluído pela Emenda Constitucional no 39/2002, está eivada de vícios desde a sua origem, como também, evidente é a afronta do Poder Constituinte Derivado aos direitos e garantias individuais dos contribuintes, por não respeitar a Constituição Federal e os princípios constitucionais tributários, sendo referido tributo consequentemente inconstitucional. 


\section{A Inconstitucionalidade da Contribuição para o Custeio de Iluminação Pública}

A constitucionalidade da Contribuição para o Custeio de Iluminação Pública foi questionada no julgamento do Recurso Extraordinário número 573675/SC, sendo o entendimento do Supremo Tribunal Federal:

EMENTA: CONSTITUCIONAL. TRIBUTÁRIO. RE INTERPOSTO CONTRA DECISÃO PROFERIDA EM AÇÃO DIRETA DE INCONSTITUCIONALIDADE ESTADUAL. CONTRIBUIÇÃO PARA O CUSTEIO DO SERVIÇO DE ILUMINAÇÃO PÚBLICA - COSIP. ART. 149-A DA CONSTITUIÇÃO FEDERAL. LEI COMPLEMENTAR 7/2002, DO MUNICÍPIO DE SÃO JOSÉ, SANTA CATARINA. COBRANÇA REALIZADA NA FATURA DE ENERGIA ELÉTRICA. UNIVERSO DE CONTRIBUINTES QUE NÃO COINCIDE COM O DE BENEFICIÁRIOS DO SERVIÇO. BASE DE CÁLCULO QUE LEVA EM CONSIDERAÇÃO O CUSTO DA ILUMINAÇÃO PÚBLICA E O CONSUMO DE ENERGIA. PROGRESSIVIDADE DA ALÍQUOTA QUE EXPRESSA O RATEIO DAS DESPESAS INCORRIDAS PELO MUNICÍPIO. OFENSA AOS PRINCÍPIOS DA ISONOMIA E DA CAPACIDADE CONTRIBUTIVA. INOCORRÊNCIA. EXAÇÃO QUE RESPEITA OS PRINCÍPIOS DA RAZOABILIDADE E PROPORCIONALIDADE. RECURSO EXTRAORDINÁRIO IMPROVIDO. I - Lei que restringe os contribuintes da COSIP aos consumidores de energia elétrica do município não ofende o princípio da isonomia, ante a impossibilidade de se identificar e tributar todos os beneficiários do serviço de iluminação pública. II - A progressividade da alíquota, que resulta do rateio do custo da iluminação pública entre os consumidores de energia elétrica, não afronta o princípio da capacidade contributiva. III - Tributo de caráter sui generis, que não se confunde com um imposto, porque sua receita se destina a finalidade específica, nem com uma taxa, por não exigir a contraprestação individualizada de um serviço ao contribuinte. IV Exação que, ademais, se amolda aos princípios da razoabilidade e da proporcionalidade. V - Recurso extraordinário conhecido e improvido (BRASIL, Supremo Tribunal Federal, RE no 573.675-0, 2009.)

O voto do Ministro Marco Aurélio, após fundamentação exponencial, era de prover o recurso do Ministério Público e declarar a inconstitucionalidade do ato normativo atacado, pelas razões seguintes.

Em princípio, a divergência na definição efetiva da natureza da COSIP, ao estabelecer que a contribuição do art. 149-A da CF não tem natureza de contribuições sociais, nem de taxa e que possui elementos compatíveis com o imposto, demonstra, nos dizeres do Ministro Marco Aurélio (BRASIL, 2009), o que é "relevante, em termos de tributos, é o conteúdo a revelar certo figurino que, para ser válido, há de guardar sintonia com a Constituição Federal."

No mesmo sentido, Ives Gandra da Silva Martins (BRASIL, 2009, p. 1442), também citado pelo Excelentíssimo Ministro, afirma que "[...] a natureza do tributo é dada por seu perfil e não por sua denominação." 
O STF decidiu que a COSIP é um: "Tributo de caráter sui generis, que não se confunde com um imposto, porque sua receita se destina a finalidade específica, nem com uma taxa, por não exigir a contraprestação individualizada de um serviço ao contribuinte" (BRASIL, 2009, p. 1404).

No entanto, a discordância da natureza da COSIP demonstra que não só a sua denominação não condiz com as suas características, mas também é possível elencar os vícios presentes desde a sua origem através da EC no 39/2002, como traduz o Ministro Marco Aurélio, apontando a inconstitucionalidade da mencionada emenda que introduziu o art. 149-A da CF:

\begin{abstract}
Em primeiro lugar, porque afastou garantia constitucional que, para mim, era uma cláusula pétrea quanto aos contribuintes: a exclusividade da União para instituir contribuições sociais e contribuição - essa contribuição seria, mas não é, ou é, sob ângulo estritamente formal e não considerado o conteúdo - no domínio econômico e de interesse das categorias profissionais. É algo que o legislador constituinte originário quis concentrado, tendo em conta a extravagância, a excepcionalidade que é a criação de contribuições outras além das previstas no corpo inicial da Carta (BRASIL, 2009, p. 1439).
\end{abstract}

Os limites do Poder Constituinte Derivado previstos na Constituição Federal não foram respeitados, pois sob análise do conteúdo do tributo e não de sua mera denominação, não poderia alterar a competência de instituir contribuições da União, pelo Congresso Nacional, para os Municípios e o Distrito Federal, através das Câmaras de Vereadores.

Ademais, o dispositivo da COSIP não é claro em determinar o critério material, critério espacial, sujeito passivo, critério quantitativo - base de cálculo e alíquota, possibilitando aos Municípios e ao Distrito Federal interpretação diversificada, como resultado da insuficiência desses elementos.

Abre-se margem ao legislador municipal na criação de uma lei que ofenda os princípios constitucionais tributários, dentre eles o princípio da isonomia, como resultado de um tratamento desigual dos contribuintes, ao estabelecer como "[...] fato gerador o consumo individual de energia elétrica e definir valores diferenciados de cobrança para contribuintes que, em tese, utilizam igualitariamente do serviço público em questão" (SILVA, 2011). 
A posição do Tribunal de Justiça de Goiás era de que em face da natureza do serviço prestado (iluminação pública), não seria possível individualizar a quantidade de energia elétrica consumida por usuário (SILVA, 2011):

EMENTA: AÇÃO DIRETA DE INCONSTITUCIONALIDADE DE LEI MUNICIPAL. CONTRIBUIÇÃO PARA O CUSTEIO DA ILUMINAÇÃO PÚBLICA. NECESSIDADE DE EDIÇÃO DE LEI COMPLEMENTAR. ISONOMIA TRIBUTÁRIA. INCONSTITUCIONALIDADE.

1) A regra estabelecida pela Constituição do Estado de Goiás em seu artigo 101, § 3ㅇ, inciso III, alínea "a", reserva à lei complementar a definição das diretrizes concernentes à incidência genérica da espécie tributária.

2) $O$ artigo 149-A da Constituição Federal não definiu, como não poderia deixar de ser, o respectivo fato gerador, base de cálculo e contribuintes do tributo nele criado, referente ao custeio da iluminação pública, tornando imprescindível a edição de lei complementar para que o mesmo possa ser instituído pelos municípios.

3) Fere o princípio da isonomia tributária, expresso no artigo 102, inciso II, da Carta Goiana, o tratamento diferenciado entre contribuintes que se encontram em situação equivalente.

4) A Constituição Estadual estabelece (artigo 104, § 3) a garantia de que nenhum outro tributo, além do ICMS, pode ser criado tendo como fato gerador "operações relativas a energia elétrica". Patente o vício constitucional decorrente da instituição da COSIP.

5) Inconstitucionalidade declarada (BRASIL, Tribunal de Justiça de Goiás, ADIN oㅡ $378-7 / 200,2008)$.

Logo, a falta de definição dos critérios tributários da COSIP do exposto do art. 149-A da CF, impossibilita a segurança na aplicação dos princípios constitucionais tributários, consequentemente, ocasiona a ofensa aos ditames da Carta Magna.

Outro ponto controvertido consiste na inconstitucionalidade da origem da COSIP, pois conforme já mencionado, referido dispositivo foi instituído através de Emenda à Constituição.

Porém, ao estabelecer um tributo que difere das demais espécies tributárias, quanto ao seu conteúdo e principalmente quanto à competência dos Municípios e do Distrito Federal de instituir o mesmo, a EC n 39/2002 modificou parte inalterável da Constituição em afronta ao que dispõe seu art. $60, \S 4$ ㅇ.

Isso porque, os princípios constitucionais tributários integram o rol das cláusulas pétreas e com a criação de um tributo não passível de clara definição, está-se diante de uma ofensa aos direitos e garantias individuais do contribuinte, interferindo em seu patrimônio, em oposição às garantias constitucionais a ele asseguradas. 
Este também é o entendimento do doutrinador Aires F. Barreto (2009, p. 518), ao expor:

[...] dentro do espectro constitucional que preside o nosso sistema tributário, conclui-se que a Emenda no 39/2002, por ter afrontado cláusulas pétreas, está insanavelmente viciada por inconstitucionalidade: primeiro porque implica a abolição dos limites do poder de reforma; derruba as balizas dessa diretriz para atribuir ao Município tributo cuja espécie a Constituição reservou à União (salvo a de sistemas de previdência); segundo, porque a emenda aniquila o direito individual de os contribuintes não serem tributados, à luz da imodificável discriminação de rendas, plasmada na Constituição.

Deste modo, notória é a inconstitucionalidade da Contribuição para o Custeio de Iluminação Pública, pois afronta direitos basilares da Constituição Federal, sendo possível o questionamento das matérias controvertidas expostas através da Ação Civil Pública a ser proposta pelo Ministério Público, por ser ente legítimo na defesa de interesses transindividuais.

\section{Da Ação Civil Pública}

A Ação Civil Pública foi pela primeira vez mencionada, em caráter legislativo, pela Lei Complementar Federal no 40 de 14 de dezembro de 1981, a denominada Lei Orgânica do Ministério Público, uma vez que a função de promover referida ação foi incluída dentre as demais atribuições do Parquet.

Em 1985, a Lei no 7.347 disciplinou a Ação Civil Pública com o objetivo de assegurar a tutela dos direitos de natureza coletiva lato sensu, classificados como de interesses coletivos stricto sensu, difusos e individuais homogêneos.

No ano de 1990, o Código de Defesa do Consumidor, Lei no 8.078/90, acresceu o inciso IV à lei supracitada e estendeu o objeto da Ação Civil Pública "a qualquer outro interesse difuso ou coletivo".

A Medida Provisória no 2.180-35 de 24 de agosto de 2001, foi a responsável por inserir o parágrafo único ao artigo 1으 da Lei 7.347/85, que dentre outras matérias, excluiu a possibilidade de propositura da Ação Civil Pública sobre a ordem tributária.

Neste contexto, compõe o quadro de bens protegidos por esta ação: o meio ambiente, o consumidor, o patrimônio histórico ou cultural, a ordem econômica, a ordem 
urbanística, ou qualquer outro interesse classificado como difuso ou coletivo. (DI PIETRO, 2009, p. 798).

Sobre a legitimidade ativa para promover a referida ação, a partir da interpretação do parágrafo 1으 do art. 129 da Constituição Federal e do artigo 5ㅇ da Lei 7.347/85, constatase que são titulares: o Ministério Público, Defensoria Pública, União, Estados, Municípios, autarquias, empresas públicas, fundações, sociedades de economia mista, bem como, associações constituídas a mais de um ano, que tenham o objetivo de proteger os bens acima mencionados, dispostos no artigo 1ạ da Lei 7.347/85. (DI PIETRO, 2009, p. 799).

Quanto à legitimidade passiva, qualquer pessoa (física, jurídica, pública ou privada) pode ser demandada. (DI PIETRO, 2009, p. 800).

No que tange à designação "Ação Civil Pública”, Maria Sylvia Zanella Di Pietro (2009, p. 796) sustenta que:

[...] justifica-se quer pela titularidade da ação (que compete ao Ministério Público, às pessoas jurídicas de direito público e às de direito privado que integram a Administração Indireta e, excepcionalmente, às entidades particulares) quer pelo seu objeto, que é sempre a defesa do interesse público ou, mais especificamente, de interesses difusos.

Para Rodolfo de Camargo Mancuso (2004, p. 23), “[...] essa ação não é 'pública' porque o Ministério Público pode promovê-la, a par de outros colegitimados, mas sim porque ela apresenta um largo espectro social de atuação, permitindo o acesso à justiça de certos interesses metaidividuais [...]." (Grifo do autor).

De acordo com o primeiro entendimento a denominação está ligada tanto aos legitimados para propositura da ação, quanto aos bens que ela agasalha. Já o segundo considera a ação como sendo Civil Pública simplesmente quando a matéria a ser resguardada vai além da esfera individual e atinge interesses coletivos, difusos e/ou individuais homogêneos.

Nesse sentido, referida ação pode ser definida como o instrumento da cidadania utilizado como o meio na defesa de interesses sociais e do patrimônio público, de direitos e interesses difusos e coletivos, como atribuição do Ministério Público e demais pessoas constitucionalmente legitimadas. 
Sua propositura decorre do dano ou da ameaça de dano a interesse difuso, coletivo ou individual homogêneo (o qual abrange tanto o dano material como o moral), bem como, a efetiva conveniência social. Para tanto, a lei traz duas modalidades de Ação Civil Pública: a principal e a cautelar.

Concretizado o dano deve haver o requerimento de condenação por perdas e danos, sendo que os valores obtidos serão destinados a reintegrar aquilo que foi danificado. Enquanto que a ação cautelar terá como objetivo a interrupção da atividade nociva, sob pena de multa diária, sempre que cabível.

A sentença oriunda dessa ação produz efeitos erga omnes, com exceção dos casos em que é julgada improcedente por falta de provas. Caso isto ocorra, caberá a qualquer outro legitimado intentar novamente idêntica ação, a fim de que seja julgado procedente o pedido frente às novas provas apresentadas.

\section{Do Interesse Difuso, Coletivo e Individual Homogêneo}

Cresce a preocupação em identificar e proteger os interesses difusos, coletivos e individuais homogêneos. A tutela dos interesses transindividuais, além de permitir uma defesa judicial coletiva, viabiliza a economia e a celeridade processual. Diante disto, é importante compreender quais são suas principais características.

Sobre o interesse difuso, Mauro Capelletti (apud, MANCUSO, 2000, p.136) ensina que é um "[...] interesse (...) à procura de um autor". Tal interesse ultrapassa o campo individual para atingir uma ordem coletiva lato sensu, o que o eleva a categoria de interesses transindividuais.

Caracteriza-se, assim, pela não apresentação de uma forma coesa, pois cuida de ideais, sentimentos coletivos ligados ao justo, ao equitativo; os chamados 'valores parajurídicos'. (MANCUSO, 2000, p. 133).

É um interesse incompatível com a existência de um titular específico, exatamente por pertencer à comunidade como um todo, por se relacionar com todos e com cada um dos titulares ao mesmo tempo e de uma só vez (MANCUSO, 2000, p. 132-133).

No intuito de abranger todas as peculiaridades dos interesses difusos, Camargo Mancuso (2000, p. 136-137) atribuiu-Ihe o seguinte conceito: 
[...] são interesses metaindividuais, que, não tendo atingido o grau de agregação e organização necessários à sua afetação institucional junto a certas entidades ou órgãos representativos dos interesses já socialmente definidos, restam em estado fluído, disperso pela sociedade civil como um todo [...] podendo, por vezes, concernir a certas coletividades de conteúdo numérico indefinido [...]. Caracterizam-se: pela indeterminação dos sujeitos, pela indivisibilidade do objeto, por sua intensa litigiosidade interna e por sua tendência à transição ou mutação no tempo e no espaço.

São interesses que vão além dos individuais, que a todos pertencem e que se encontram dispersos pela sociedade de maneira geral. Identificam-se pela não determinação de seus titulares, do seu objeto e por serem mutáveis no tempo e no espaço.

Frente à extensão do objeto e dos titulares, qualquer classificação, enquadramento ou conceituação objetiva do que vem a ser interesse difuso, não mais se trataria de um algo difuso, mas de um interesse coletivo strictu sensu.

Assim, em conformidade com o artigo 81, incisos I e II, parágrafo único, do Código de Defesa do Consumidor, o interesse coletivo difere do difuso no que concerne à origem da lesão e pela abrangência do grupo atingido.

No interesse difuso, os titulares são indeterminados, porém ligados por uma circunstância de fato. Enquanto que no interesse coletivo, o titular pertence a um grupo, categoria ou classe de pessoas ligadas entre si ou com a parte contrária por uma relação jurídica básica (ALMEIDA, 2003, p. 188).

Quanto ao interesse individual homogêneo, de acordo com o artigo 81, parágrafo único, inciso III, do Código de Defesa do Consumidor, pode ser definido como "[...] aqueles de grupo, categoria ou classe de pessoas determinadas ou determináveis, que compartilhem prejuízos divisíveis, de origem comum, normalmente oriunda da mesma circunstância de fato" (MAZZILLI, 2007, p. 53). Em sentido amplo, o interesse individual homogêneo faz parte do interesse coletivo.

Em suma, os interesses difusos e os coletivos assemelham-se por serem indivisíveis e distinguem-se no que concerne à titularidade material e o fundamento. Ao passo que o interesse individual homogêneo, é divisível, de origem comum, com sujeitos determináveis e com a disponibilidade de direito (GALVÃO, 2003, p. 200-201).

Vale salientar que o interesse difuso, o coletivo em sentido estrito e o individual homogêneo são passíveis de serem lesados concomitantemente. A Ação Civil Pública, nesse caso, deverá discutir todos os interesses em um só processo. 


\section{Do Ministério Público}

O Ministério Público, consoante se depreende do caput do artigo 127 da Constituição Federal, é uma "[...] instituição permanente, essencial à função jurisdicional do Estado [...]", com a incumbência de resguardar a ordem jurídica, o regime democrático e os interesses sociais e individuais indisponíveis. Em outras palavras, é o instituto encarregado de proteger os direitos fundamentais do Estado Democrático de Direito.

Evidencia-se tal proteção quando os membros que compõem o Ministério Público agem: no âmbito penal, na repressão de crimes; na esfera cível, ao abrigar determinadas instituições, bens, valores fundamentais e pessoas; no controle externo da atividade policial; na "[...] requisição de diligências investigatórias e na instauração de inquérito policial [...]", etc. (SILVA, 2005, p. 602-603).

Por conseguinte, a família, o meio ambiente, os valores artísticos, estéticos, históricos, os consumidores e incapazes, são alguns dos interesses sociais que estão sob o manto protetivo do Parquet. (CINTRA; GRINOVER; DINAMARCO, 2008, p. 228).

Embora exerça funções indispensáveis ao Poder Judiciário, o Ministério Público não o integra. Trata-se, pois, de um órgão autônomo, segundo o qual o princípio da unidade e o princípio da independência funcional norteiam sua organização.

O princípio da unidade se pauta na ideia de que todos os membros estão sujeitos a uma só ordem ou corporação, o que permite a substituição de uns pelos outros nas suas funções, sem que haja modificação nos processos em que oficiam. Desta forma, os membros que fazem parte do órgão em questão personificam a instituição, independentemente da função que exerçam.

Quanto ao princípio da independência funcional, este corresponde à discricionariedade que os membros possuem para seguirem a sua consciência jurídica, embasados tão somente no direito.

E uma das principais características do Ministério Público é o dever de agir e não o direito. Identificada a hipótese de lesão ou ameaça de lesão, em que está presente a legitimidade do Parquet, há obrigatoriedade e indisponibilidade de ação. Cumpre dizer que ele possui ampla liberdade para verificar se estão ou não presentes as hipóteses em que a sua ação é compulsória. (MAZZILLI, 2004, p. 81). 
Para tornar viável, portanto, o desempenho eficiente do Ministério Público, a ele foi concedido independência funcional e autonomia financeira, qualidades estas imprescindíveis na luta pelo bom funcionamento dos serviços públicos e para propositura de ações em prol de interesses difusos.

\section{Da Legitimidade do Ministério Público para Propor Ação Civil Pública em Matéria Tributária - COSIP}

A Medida Provisória no 2.180-35, de 24 de 2001, ao acrescentar o parágrafo único ao artigo 10 da Lei 7.347/85, vetou a propositura da Ação Civil Pública em matéria tributária ao dispor:

Art. 1ㅇ. Regem-se pelas disposições desta Lei, sem prejuízo da ação popular, as ações de responsabilidade por danos morais patrimoniais causados: [...] IV - a qualquer outro interesse difuso ou coletivo. [...]. Parágrafo único - Não será cabível ação civil pública para veicular pretensões que envolvam tributos [...]. (BRASIL, 1985, grifo nosso.).

Diante do veto, a expressão 'qualquer outro interesse difuso ou coletivo' perdeu o sentido, logo que ficaram desprovidos de tutela os direitos dos contribuintes lato sensu, os quais, segundo Camargo Mancuso, sentem o peso da atual "[...] sanha fiscal insaciável." (2004, p. 45). Prova de que o sistema jurídico do País está longe de possibilitar o justo e amplo acesso ao interesse difuso e coletivo.

Nigro Mazzilli (2004, p. 131) afirma:

[...] se a ação civil pública ou coletiva não estiverem a usurpar papel que não lhes é próprio, nada deve impedir sejam usadas para a defesa coletiva de quaisquer interesses transindividuais, mesmo que de natureza tributária ou qualquer outra. Assim, por exemplo, não se deve impedir, em tese, que uma associação civil de funcionários ajuíze ação civil pública destinada a obter o cancelamento de lançamentos de um imposto sobre seus associados, se esse tributo tiver sido fixado de forma inconstitucional. (Grifo nosso).

Quando há a necessidade de proteção dos interesses transindividuais e esteja presente a efetiva conveniência social, sem que a Ação Civil Pública ou Coletiva usurpe função alheia, não há que se falar em restrição legal de matéria.

Sobre este assunto, IImar Galvão (2003, p. 2004) declara: 
[...] o Ministério Público não apenas pode, mas deve assumir a defesa de quaisquer direitos ou interesses, sempre que revelada conveniência para a sociedade como um todo, independentemente de tratar-se de interesses e direitos que podem, por igual, ser judicialmente defendidos por eventuais prejudicados facilmente identificáveis. (Grifos do autor).

Deve haver a real conveniência na atuação ministerial em razão de efetiva proteção aos interesses transindividuais. Deste modo, o cabimento será avaliado de acordo com a natureza do dano, os sujeitos sobre os quais recai este dano e em razão do interesse social em reparar, impedir ou obstar a continuidade da lesão.

Nesta linha de raciocínio, Maria Sylvia Zanella Di Pietro (2009, p. 789) declara: “A norma, a toda evidência, não pode prevalecer nas situações em que estejam presentes os requisitos constitucionais para a propositura da ação [...]". A lei, nesse tocante, deve promover a justiça e não obstá-la.

Segundo este posicionamento, desde que presentes os requisitos que ensejam a propositura da ação e que seja respeitado o fim a que se destina o Ministério Público, pouco importa as matérias a serem tratadas, sejam elas sobre previdência social, captação de poupança popular, questões tributárias etc (MAZZILLI, 2004, p. 98).

Vale frisar que as ações de natureza coletiva têm, dentre outras, a função de evitar que inúmeros processos individuais sobrecarreguem e travem o Poder Judiciário, além de impedir que decisões divergentes sobre a mesma matéria provoquem o descrédito na própria justiça (MAZZILLI, 2004, p. 131).

Sobre a Contribuição para o Custeio de Iluminação pública, o Ministério Público tem legitimidade para promover Ação Civil Pública com vistas a obstar a cobrança deste tributo, frente à conveniência social, os interesses transindividuais envolvidos e o princípio do acesso à justiça. Assim, discutir a legalidade da COSIP, em sede de Ação Civil Pública, é imprescindível.

Devido à capacidade econômica, a maioria dos contribuintes encontra-se impossibilitada de demandar judicialmente sobre a legalidade da cobrança do referido tributo.

Conforme preceitua o artigo 5, inciso XXXV, da Constituição Federal, "a lei não excluirá da apreciação do Poder Judiciário lesão ou ameaça a direito", sendo que o não 
debate deste tema, portanto, na esfera coletiva, implica na violação do princípio do acesso à justiça (STF, RESP. 729.399, Relator: Min. Luiz Fux, 2006).

Mesmo que todos os contribuintes tivessem como acionar o Poder Judiciário, a lentidão das prestações jurisdicionais aumentaria proporcionalmente ao número de processos. E é exatamente para evitar tais embaraços que existem as ações de natureza coletiva.

Infelizmente a jurisprudência majoritária entende como descabida a propositura da Ação Civil Pública em matéria tributária (SCARTEZZINI, 2003, p. 17). Todavia, esta questão deve ser debatida e revista, pois não se pode olvidar que o reconhecimento da legitimidade do Ministério Público em propor Ação Civil Pública em matéria tributária, no caso a COSIP, não só facilitaria o acesso à justiça, como também reduziria o número de demandas que tanto tumultuam o judiciário brasileiro.

Espera-se, assim, que a evolução do pensamento sobre a defesa dos direitos coletivos seja acompanhada dos meios capazes e eficientes de promover tal proteção.

\section{Conclusão}

A COSIP prevista no art. 149-A da CF, desde sua origem através da Emenda Constitucional no 39/2002, demonstrou ofensas aos direitos e princípios basilares da Constituição.

Inicialmente, com a exposição das correntes doutrinárias sobre o questionamento do caráter da COSIP, tornou-se possível o entendimento de que mera denominação do tributo não retrata suas características, tendo a mesma conteúdo para uns de taxa, para outros de imposto.

Outro fator que possibilitou a discussão do tema foi a constatação da falta de elementos que determinem de forma expressa os critérios tributários, quais sejam, material, espacial, quantitativo, bem como, seu sujeito passivo.

A insuficiência desses elementos resulta na possibilidade dos Municípios e do Distrito Federal, ao instituir a referida contribuição, violar os princípios constitucionais tributários, dentre eles, o princípio da isonomia tributária. 
Portanto, da explanação sequente, foi possível notar que a COSIP afronta os direitos e princípios constitucionais, pois desrespeita os limites impostos na Constituição Federal no que se refere a sua alteração, sendo, por conseguinte, inconstitucional.

O Ministério Público, a fim de evitar que milhares de processos individuais sobrecarreguem e obstruam o Poder Judiciário e, impedir que as decisões contrárias, sobre idêntica matéria julgada, com base nos mesmos preceitos, suscitem o descrédito na justiça nacional, deve questionar a COSIP através de Ação Civil Pública; ação adequada a ser proposta na defesa dos interesses sociais, do patrimônio público, dos direitos e interesses difusos e coletivos.

Não obstante seja um órgão autônomo e independente, o Ministério Público possui obrigação de agir em todos os casos em que haja a efetiva conveniência social, bem como o dano ou a ameaça de dano a interesse transindividual. Presente a legitimidade do Parquet, a ação torna-se obrigatória e indisponível.

A Medida Provisória no 2.180-35/ 2001 fez com que a expressão "qualquer outro interesse difuso ou coletivo" perdesse amplitude e, consequentemente, limitou a atuação do Ministério Público. O efeito dessa restrição trouxe como resultado a impossibilidade do sistema jurídico pátrio assegurar a ampla defesa dos interesses difusos e coletivos. E a norma não pode limitar o acesso à justiça - princípio expresso no art. 5o, XXXV, da Constituição Federal - uma vez que identificados todos os elementos constitucionais da ação, esta deve ser proposta e apreciada no mérito.

Conclui-se do presente artigo que o Ministério Público deve assumir a defesa de quaisquer direitos ou interesses, sempre que presentes os requisitos que ensejam à propositura da ação, revelada a conveniência para a sociedade e respeitado o fim a que se destina mencionado órgão, sendo ente legitimado para propor a Ação Civil Pública referente à COSIP, com vistas à tutelar os interesses transindividuais e a respeitar o princípio do acesso à justiça.

\section{Referências}

ALMEIDA, João Batista de. Manual de direito do consumidor. São Paulo: Saraiva, 2003. 
ARAUJO, Luiz Alberto David; VIDAL, Serrano Nunes Junior. Curso de direito constitucional. 12. ed. São Paulo: Saraiva, 2008.

BARRETO, Aires F. Curso de Direito Tributário Municipal. São Paulo: Saraiva, 2009.

BONFIM, Paulo Andreatto. Os princípios constitucionais tributários e o poder constituinte derivado. Jus Navigandi, Teresina, ano 9, n. 360, 2 jul. 2004. Disponível em: <http://jus.com.br/revista/texto/5416>. Acesso em: 21 nov. 2011.

BRASIL. Código Tributário Nacional. Organização dos textos de Antonio Luiz de Toledo Pinto. 9. ed. São Paulo: Saraiva, 2010a.

. Constituição (1988). Constituição da República Federativa do Brasil. 9. ed. São Paulo: Saraiva, 2010b.

. Presidência da República, Subchefia para Assuntos Jurídicos. Lei no 7.347, de 24 de julho de 1985. Disciplina a ação civil pública de responsabilidade por danos causados ao meio-ambiente, ao consumidor, a bens e direitos de valor artístico, estético, histórico, turístico e paisagístico (VETADO) e dá outras providências. Brasília, DF; 1998. Disponível em: <http://www.planalto.gov.br/ccivil_03/leis/L7347Compilada.htm>. Acesso em: 28 jul. 2012.

. Súmula no 670 do Supremo Tribunal Federal, de 24 de setembro de 2003. Diário Oficial da República Federativa do Brasil, Brasília, 09 de out. 2003.

. Superior Tribunal de Justiça. Recurso Especial no 729.399. Recorrente: Município de São Paulo. Recorrido: Instituto Brasileiro de Defesa do Consumidor - IDEC. Relator: Min. Luiz Fux. Brasília, 21 de março de 2006. Disponível em: < http:/ www.stf.jus.br >. Acesso em: 17 nov. 2011.

. Supremo Tribunal Federal. Recurso extraordinário no 573.675-0. Recorrente:

Ministério Público do Estado de Santa Catarina. Recorrido: Município de São José. Relator: Min. Ricardo Lewandowski. Brasília, 22 de maio de 2009. Disponível em: <http:/ www.stf.jus.br>. Acesso em: 20 nov. 2011.

. Tribunal de Justiça de Goiás. ADIN no 378-7/200 (200705168276). Recorrente: Procurador Geral de Justiça do Estado de Goiás. Recorrido: Município de Ceres. Relator: Paulo Teles. Goiânia, 08 de outubro de 2008. Disponível em: < http://www.mp.go.gov.br/portalweb/hp/16/docs/cosip_ceres_-_final.pdf $>$. Acesso em: 10 nov. 2011.

CARRAZZA, Roque Antonio. Curso de Direito Constitucional Tributário. 26. ed. São Paulo: Malheiros Editores, 2010. 
CARVALHO, Paulo de Barros. Curso de Direito Tributário. 23. ed. São Paulo: Saraiva, 2011.

CINTRA, Antônio C. de A.; GRINOVER, Ada Pellegrini; DINAMARCO, Cândido R. Teoria geral do processo, ed. 24. São Paulo: Malheiros Editores, 2008.

DI PIETRO, Maria Sylvia Zanella. Direito administrativo. 22. ed. São Paulo: Atlas, 2009.

ILMAR, Galvão. Ação civil pública e controle de constitucionalidade. WALD, Arnoldo (coord.). Aspectos polêmicos da ação civil pública. São Paulo: Saraiva 2003.

MANCUSO, Rodolfo de Camargo. Ação civil pública: em defesa do meio ambiente, do patrimônio cultural e dos consumidores: Lei 7.347/85 e legislação complementar, ed. 9. São Paulo: Revistas dos Tribunais, 2004.

. Interesses difusos: conceito e legitimação para agir. 5. ed. São Paulo: Revistas dos

Tribunais, 2000.

MARTINS, Ives Gandra da Silva. As Contribuições no Sistema Tributário Brasileiro. In. MACHADO, Hugo de Brito (org.). As Contribuições no Sistema Tributário Brasileiro. Fortaleza: Instituto Cearense de Estudos Tributários - ICET, 2003.

MAZZILLI, Hugo Nigro. A defesa dos interesses difusos em juízo: meio ambiente, consumidor, patrimônio cultural e outros interesses. 17. ed. São Paulo: Saraiva, 2004.

A defesa dos interesses difusos em juízo: meio ambiente, consumidor, patrimônio cultural, patrimônio público e outros interesses. 20. ed. São Paulo: Saraiva 2007.

MELO José Eduardo Soares de. Contribuições Sociais no Sistema Tributário. 5. ed. São Paulo: Malheiros Editores, 2006.

SCARTEZZINI, Ana Maria. Ação civil pública. WALD, Arnoldo (coord.). Aspectos polêmicos da ação civil pública. São Paulo: Saraiva, 2003.

SILVA, Edimar Gomes da. Contribuição de lluminação Pública e o Princípio da Isonomia Tributária. In: Âmbito Jurídico, Rio Grande, 89, 01/06/2011. Disponível em $<$ http://www.ambito-juridico.com.br>. Acesso em 21/11/2011.

SILVA, José Afonso de. Curso de direito constitucional positivo. 25. ed. São Paulo: Malheiros, 2005. 
VELLOSO, Carlos Mário da Silva. Processo judicial tributário: medidas judiciais que o integram e a legitimidade do Ministério Público para a ação civil pública que tem por objeto o não pagamento de um tributo. WALD, Arnoldo (coord.). Aspectos polêmicos da ação civil pública. São Paulo: Saraiva, 2003.

Artigo recebido em 13/08/2012 e aprovado para publicação em 30/11/2012. 
